\title{
Feasibility of a psychoeducational group intervention to improve parental reflective functioning and bonding in pregnancy: a randomised trial
}

Article

Accepted Version

Cox, H., James, A., Day, C. and Reissland, N. (2021)

Feasibility of a psychoeducational group intervention to improve parental reflective functioning and bonding in pregnancy: a randomised trial. Journal of Reproductive and Infant Psychology, 39 (5). pp. 499-515. ISSN 0264-6838 doi: https://doi.org/10.1080/02646838.2020.1786036 Available at https://centaur.reading.ac.uk/91660/

It is advisable to refer to the publisher's version if you intend to cite from the work. See Guidance on citing.

To link to this article DOI: http://dx.doi.org/10.1080/02646838.2020.1786036

Publisher: Taylor \& Francis

All outputs in CentAUR are protected by Intellectual Property Rights law, including copyright law. Copyright and IPR is retained by the creators or other copyright holders. Terms and conditions for use of this material are defined in the End User Agreement. 


\section{www.reading.ac.uk/centaur}

\section{CentAUR}

Central Archive at the University of Reading

Reading's research outputs online 
1 Feasibility of a psychoeducational group intervention to improve parental reflective

$5 \quad$ OEX

6 Email. Hannah.cox.2015@live.rhul.ac.uk

7 Telephone: 07580107764

$8{ }^{2}$ School of Psychology and Clinical Language Sciences, University of Reading, Earley Gate, 9 Whiteknights Road, Reading RG6 6AL

$10{ }^{3}$ Centre for Parent and Child Support, South London and Maudsley NHS Foundation Trust, 11 Michael Rutter Centre, De Crespigny Park, Camberwell, London SE5 8AZ

$12{ }^{4}$ Department of Psychology, Durham University, South Road, Durham DH1 3LE

\section{Author contributions}

$14 \mathrm{HC}, \mathrm{CD}$ and AJ developed the Baby CHAT group and its materials and designed the study.

$15 \mathrm{HC}$ and $\mathrm{CD}$ completed the groups and collected data. $\mathrm{HC}$ was responsible for data analysis, interpretation and drafted and revised the manuscript. CD and AJ supervised the study and

17 revised the manuscript.NR helped with the development of Baby CHAT group material by providing and thinking about how we could incorporate scan video footage, also advised on

19 how to recruit and access participants and study design.

\section{Compliance with ethical standards}

21 Ethical consent was gained from the National Research Ethics Service and the Health 
23 Informed consent was obtained from all individual participants included in the study. Royal

24 Holloway, University of London ethical approval was also sought.

\section{Geolocation information}

26 This study took place in South-East London.

\section{Acknowledgments}

28 Thank you to all the parents that took part in the study along with staff at midwifery units

29 who helped with recruitment. In particular we would like to thank Jill Demilew (Consultant

30 Midwife) for her knowledge and enthusiasm, and helping to set up Baby CHAT groups.

31 Thank you to Dr. Oliver Schauman, Prof. Dawn Langdon and Dr. Polly Waite for your useful

32 comments during the write up of this study.

33 


\title{
Feasibility of a psychoeducational group intervention to improve parental reflective
}

functioning and bonding in pregnancy: A randomised trial

\author{
Abstract \\ Objective: To develop and evaluate Baby CHAT, a single-session psychoeducational \\ intervention for expectant parents. Baby CHAT aims to improve parental reflective \\ functioning (RF) and bonding.
}

Background: The early years of a child's life, including pregnancy, are vital for healthy physical and emotional development. Caregivers who provide responsive and positive parenting, enhanced through strong bonds and good reflective functioning (RF), can aid healthy development of their children. However, limited interventions exist aimed at enhancing RF and bonding in expectant mothers and fathers.

Methods: The feasibility of Baby CHAT was assessed using a mixed methods randomised controlled trial (RCT) design. It evaluated uptake and retention of participants, effect size calculations, and acceptability and satisfaction with Baby CHAT.

Results: Participants $(\mathrm{N}=20)$ were aged 30-39 years $(\mathrm{n}=17)$ in their third trimester of pregnancy $(n=12)$. Nine males and 11 females were recruited. Content analysis of qualitative feedback after the intervention resulted in four themes; positive group aspects, group improvements, 4D scan footage, and relating content to my baby.

Conclusions: Findings indicated that Baby CHAT is enjoyable and useful in helping expectant parents think about baby as a separate person, with potential to improve prenatal RF and bonding. However, further research is required to assess the effectiveness of Baby CHAT to improve bonding and RF. Future studies should investigate Baby CHAT with an adequately powered study. 
61 Keywords: reflective functioning; bonding; parenting intervention; pregnancy; antenatal; 4D 62 scans 
63 IntroductionReflective functioning (RF), an individual's ability to think about and interpret

64

65

67

their own and others' actions (Bateman \& Fonagy, 2010) and bonding, feelings of an expectant mother or father towards their baby (Pretorius et al., 2005), can positively improve early parent-child relationships. Developing good RF in pregnancy means parents can imagine their unborn fetus as a baby and themselves as parents (Slade, Grienenberger, Bernbach, Levy \& Locker, 2005), facilitating positive transitions into parenthood. When developed prenatally, RF can help develop stronger parental-child bonds (Sadler, Novick \& Meadows-Oliver, 2016). Parental bonding begins before birth (Glover \& Capron, 2017) with strong maternal-fetal bonds predicting better physical health behaviours during pregnancy and maternal mental health (Lindgren, 2001) as well as enhancing post-natal bonds (Rossen et al., 2016). This has potential to increase responsive and sensitive care (Foley \& Hughes, 2018). Parents with difficulty developing RF or bonding with their babies (Taylor, Atkins, Kumar, Adams \& Glover, 2005) can be helped with parenting interventions.

\section{Reflective functioning interventions}

A number of parenting interventions to improve RF have been proposed. These include a post-natal psychoeducational group, Family-Minds (Bammens, Adkins, \& Badger, 2015), that significantly improved parental RF by helping parents understand their own and others' mental states. The Minding the Baby (MTB) (Sadler et al., 2016) intervention, encouraged RF by narrating parent-child interactions to help parents consider how they and baby were feeling. Mothers in the intervention group compared with controls increased their ability to reflect.

Fewer RF interventions have been developed for pregnancy. The Peep Reflective Parenting Programme (Maskell-Graham, 2014) for expectant mothers (28-30 weeks' gestation) aimed to enhance RF, bonding, and confidence, through helping mothers 
understand their baby's experience, supporting them to recognise and respond to baby's behaviours. In their sample of ten mothers RF was enhanced.

\section{Bonding interventions}

An attachment-based antenatal group 'Mellow Bumps' (Breustedt \& Puckering, 2013), delivered at 20-30 weeks gestation, aimed to decrease mothers' stress and increase parent-child bonding. Unstructured interviews with four mothers with one or more risk factors indicated reduced anxiety and depression. However, the authors did not include any objective measurements for prenatal bonding.

Studies using ultrasounds have shown that four-dimensional (4D) scans can help parents visualize their fetus as a baby and evoke strong feelings of happiness and excitement (Ji et al., 2005). Two-dimensional (2D), three-dimensional (3D) and 4D scans, are associated with increased prenatal bonding in mothers (deJong-Pleij et al., 2013; Righetti, Dell'Avanzo, Grigio \& Nicolini, 2005; Rustico, Baietti, Coviello, Orlandi \& Nicollini, 2005) but not fathers (Righetti et al., 2005). Providing a context and understanding to scan images can enhance parent-fetus bonding by increasing understanding of the images by mothers and fathers, and help inform stories about the unborn child's experience (Roberts, 2012). This suggests, adding an explanatory context to scans may help prenatal bonding. Stronger bonds in pregnancy can enhance healthy maternal behaviours for example exercising, eating a healthy diet and smoking cessation (Lindgren, 2001).

\section{Developing a new intervention}

Most studies examining parenting interventions enhancing bonding and RF are conducted post-birth, however, promoting prenatal bonding is crucial (Daglar \& Nur, 2018) because prenatal interventions improve the quality of post-natal relationships (Siddiqui \&

110 Hagglöf, 2000). Furthermore, interventions often fail to include fathers, their approaches and

111 formats vary and none are designed to improve both bonding and RF. Those delivering 
112 prenatal care are vital in assessing and promoting maternal-fetal bonding (Daglar \& Nur,

113 2018) however, there are funding and time constraints. No current antenatal psychological

114 intervention can be delivered in a single session, making it cost-effective and a simple

115 addition to existing antenatal care. In the current study, we aim to address this gap in the

116 literature by assessing feasibility of a new intervention.

117 Research using 4D ultrasounds has shown fetuses from 32-weeks show "proto

118 imitation" of mouth movements, when hearing specific sounds (Reissland, Francis,

119 Buttanshaw, Austen \& Reid, 2016). Indeed, fetuses habituate to sound and light stimulation,

120 and thereby possibly their memory for such stimulation (Reissland, Francis, Froggatt,

121 Reames \& Girkin, 2018). Additionally, fetal reactions to crossmodal stimulation is affected

122 by maternal anxiety and depression (Reissland et al., 2018). Hence, this and other research

123 indicates that fetuses react to stimulation and are preparing to interact socially, pre-birth

124 (Reissland et al., 2016). We propose incorporating this 4D video footage in a

125 psychoeducational teaching tool to augment textually delivered information, thereby

126 increasing its effectiveness in helping parents to apply taught content to their baby.

127 Visualizing the fetus could help parents conceptualise their baby as a social being with

128 individual characteristics, which are hypothesized to improve RF (primary outcome) and

129 prenatal bonding, as well as maternal health behaviours (secondary outcomes).

130 This paper describes development and evaluation of 'Baby CHAT', a novel, single-

131 session group antenatal intervention, incorporating 4D scan video footage developed by

132 Reissland (2017). It aims to improve RF by helping parents think about the experience and

133 characteristics of their unborn baby and improve pre-natal bonding by encouraging parents to

134 do activities with baby pre-birth to enhance emotional ties and feelings of closeness.

135 Enhancing maternal-fetal bonds should improve maternal health behaviours. 

methods for a subsequent trial in order to understand whether Baby CHAT could improve RF

140 and/or bonding. This study aimed to generate descriptive statistics to assess the feasibility of proposed methods and intervention, rather than establishing efficacy or generalisability. In order to test the feasibility of Baby CHAT we assessed: 1) uptake and retention by expectant parents; 2) acceptability of, and satisfaction with, Baby CHAT; and 3) calculation of effect sizes to aid future sample sizes.

\section{Method}

146 Design

Mixed-methods randomised controlled design to test feasibility of research evaluation methods and acceptability of Baby CHAT.

\section{Participants}

Opportunity sample $(\mathrm{N}=20)$ recruited from two maternity units in South-East London, following normal 20 -week anomaly scans, for single or multiple pregnancies. Both couples and single parents, including those without their partners. Data was collected from expectant mothers and fathers. See results (Table 4) for full participant information.

\section{Intervention development and delivery}

The 60-minute 'Baby CHAT' intervention comprised psychoeducational material and was adapted from existing guidelines (Day et al., 2014; see Table 1 for session plan). A

157 Clinical Psychologist and a Trainee Clinical Psychologist facilitated groups. Fidelity was ensured using the session plan during groups and fidelity checklist following groups. If adopted into routine practice, Psychologists, Nurses or Midwives could deliver groups. 
Baby CHAT session plan

\begin{tabular}{ccc}
\hline Section & $\begin{array}{c}\text { Time } \\
(\text { mins })\end{array}$ & Content \\
\hline
\end{tabular}

1. Welcome

10

2. Social and

unique baby

3. Four-

Dimensional

scan research
- Introductions

- Overview of Baby CHAT

- Confidentiality

- Participants share something they are looking forward to about meeting their baby.

- Baby CHAT booklet given

- Presentation of information about social development of a baby post-birth (Belsky \& De Haan, 2011; Maggi, Irwin, Siddiqi \& Hertzman, 2010; NHS Choices, 2016).

- Video of a six-week old baby interacting with her parents (displaying early baby 'chat')

- Video material showing reciprocal parent-baby interactions highlighted and group discussion encouraged.

- Parents asked to consider when baby's social development occurs, for example before or after birth.

- Presented with information about fetal development during pregnancy (NHS Choices, 2017a; Reissland et al., 2016).

- Video clip 'Your unborn baby and you' (Reissland, 2017), containing 4D-ultrasound images of fetuses mouthing sounds presented outside the womb.

- Discussion encouraged, to help parents think about social development of babies from 32-weeks.

- This could enable parents to consider unborn babies as individuals, with their own experiences to encourage reflective thinking.

- Think about baby getting ready for when they meet them.

4. Getting to 5 know your baby
- Parents were asked to think about and visualise characteristics of their own baby for example routine 


\begin{tabular}{|c|c|c|}
\hline & & $\begin{array}{l}\text { in the womb, likes and dislikes, bump name (NHS } \\
\text { Choices, 2017b; Hijazi \& East, 2009). } \\
\text { - What have you learnt about your baby so far? } \\
\text { - What do you think their personality and temperament } \\
\text { is like? } \\
\text { - What do you think baby is doing in the womb? } \\
\text { This was to encourage RF by asking parents to think } \\
\text { about the experience of their baby (RF) and to further } \\
\text { develop feelings of connection (bonding). }\end{array}$ \\
\hline $\begin{array}{l}\text { 5. Baby CHAT } \\
\text { (doing things } \\
\text { together) }\end{array}$ & 10 & $\begin{array}{l}\text { - Discussion around activities parents can do with baby } \\
\text { before birth for example: } \\
\circ \text { singing } \\
\circ \text { reading } \\
\circ \text { talking } \\
\circ \text { playing music } \\
0 \text { mindfulness } \\
\text { - Thinking about good times to do these activities for } \\
\text { example choosing more upbeat music if baby is } \\
\text { awake and moving around, more sedate activities } \\
\text { when baby is less active. } \\
\text { Aim to encourage parents to think about developing a } \\
\text { stronger connection with baby (bonding) and about } \\
\text { their baby's experience when choosing activities } \\
\text { (RF). } \\
\text { Plan when/where/how parents will have a go at one } \\
\text { or more of these activities. }\end{array}$ \\
\hline 6. Ending & 5 & $\begin{array}{l}\text { - Ask everyone to write something positive they will } \\
\text { take away from the session about their baby's } \\
\text { development. } \\
\text { - Aim to reinforce key messages and leave parents with } \\
\text { positive feelings at the end of the group. }\end{array}$ \\
\hline
\end{tabular}

Measures

Descriptive data collected about age, sex, ethnicity, education, employment status,

167 previous mental health difficulties, and pregnancy details. A questionnaire about current

168 parental mental health was included: 
Hospital Anxiety and Depression Scale (HADS) (Zigmond \& Snaith, 1983)

Fourteen-item (rated 0-3) self-report scale. Scores range from: 0 (no anxiety/depression) to 21 (severe anxiety/depression). It screens out physical or somatic symptoms of depression (Bjelland, Dahl, Haug \& Neckelmann, 2002) making it suitable for pregnant populations (Lee et al., 2007). It has good internal consistency for anxiety $(\alpha=.83)$ and depression $(\alpha=.82)$ and very good concurrent validity when compared against other common questionnaires (Bjelland et al., 2002).

\section{Feasibility outcomes}

The following information was recorded:

- Participant uptake and retention

- Rates of eligible participants

- Data collection and missing data

- Feasibility of intervention delivery

\section{Baby CHAT feedback form}

The feedback included 9 questions, 3 closed asking about duration of intervention (too long/about right/too short), timing of the intervention during pregnancy (too early/about right/too late) and whether participants attended with a partner (yes/no) and 8 open-ended questions. The questionnaire aim was to gather participants' views on the intervention, for example usefulness of Baby CHAT, 4D scan footage inclusion, and improvements.

\section{Fidelity Checklist}

Facilitators recorded information on the setting, questionnaires, session materials, initiation and ending of the group, materials and discussions, after completing groups.

\section{Clinical Outcomes}

Primary and secondary outcomes were assessed using validated questionnaires. 
2015). Fourteen-item self-report measure to assess parental ability to imagine their fetus as a

196

197

198

199

200

201

baby. Respondents rate statements relating to their unborn baby on a seven-point likert scale

(1= strongly disagree to $7=$ strongly agree $)$ with a maximum score of 98 . Higher scores represent stronger prenatal RF. The P-PRFQ has acceptable internal consistency $(\alpha=.77)$ and good construct validity, compared to the Pregnancy Interview (Slade, Grunebaum, Huganir, \& Reeves, 2011).

\section{Secondary outcomes}

Maternal and paternal antenatal attachment scales (MAAS/PAAS, Condon, 1993).

Nineteen-item for mothers and 16-item for fathers, self-report scales to measure attitudes, feelings and behaviours towards their fetuses. A likert scale (1-5) captures responses, with stronger attachments indicated by higher scores. Maximum scores differ for the MAAS=95 and PAAS=80. Both measures have good internal consistency (PAAS, $\alpha=.83$; MAAS, $\alpha=.82$; Condon, 1993) and provide a good measure of overall bonding (Condon \& Corkindale, 1998).

Prenatal Health Behaviours Scale (PHBS) (Deluca \& Lobel, 1995). Twenty-item scale for expectant mothers to report their pregnancy behaviours. A 5 -point scale $(0=$ never to 4=very often) captures responses, with more healthful behaviours indicated by higher scores (maximum score=80). It has good reliability and validity (DeLuca \& Lobel, 1995; Lobel, DeVincent, Kaminer \& Meyer, 2000; Lobel et al., 2008).

\section{Procedure}

Participants were recruited using posters and leaflets, by midwives at routine appointments, from waiting rooms and antenatal workshops. Those who provided contact details were contacted after a minimum of 48-hours, so they could reflect on the project. Interested and eligible participants completed and returned consent forms. Participants were 
219 randomised, using simple randomisation on a computer programme. Groups were held in

220 meeting rooms at a maternity wing.

221 Intervention group. At the beginning of the group, participants completed a

222 background questionnaire and baseline measures (time 1). At the end of the group meeting,

223 they completed post-measures (time 2). Two-weeks later they completed follow-up measures

224 (time 3) via email or post (see Table 2).

225 Table 2

226 Intervention questionnaires completed across time-points

\begin{tabular}{lcccccc}
\hline & \multicolumn{3}{c}{ Mothers } & \multicolumn{3}{c}{ Fathers } \\
\cline { 2 - 7 } & Time 1 & Time 2 & Time 3 & Time 1 & Time 2 & Time 3 \\
HADS & $\sqrt{ }$ & $\sqrt{ }$ & $\sqrt{ }$ & $\sqrt{ }$ & $\sqrt{ }$ & $\sqrt{ }$ \\
P-PRFQ & $\sqrt{ }$ & $\sqrt{ }$ & $\sqrt{ }$ & $\sqrt{ }$ & $\sqrt{ }$ & $\sqrt{ }$ \\
MAAS/PAAS & $\sqrt{ }$ & $\sqrt{ }$ & $\sqrt{ }$ & $\sqrt{ }$ & $\sqrt{ }$ & $\sqrt{ }$ \\
PHBS & $\sqrt{ }$ & & $\sqrt{ }$ & & & \\
Feedback form & & $\sqrt{ }$ & & & & \\
\end{tabular}

Wait-list control. Wait-list control participants completed the background

questionnaire and baseline measures (time 1) via post or email. Two-weeks later they group. 


\begin{tabular}{lcccc} 
& \multicolumn{2}{c}{ Mothers } & \multicolumn{2}{c}{ Fathers } \\
\cline { 2 - 5 } & Time 1 & Time 2 & Time 1 & Time 2 \\
\hline HADS & $\sqrt{ }$ & $\sqrt{ }$ & $\sqrt{ }$ & $\sqrt{ }$ \\
P-PRFQ & $\sqrt{ }$ & $\sqrt{ }$ & $\sqrt{ }$ & $\sqrt{ }$ \\
MAAS/PAAS & $\sqrt{ }$ & $\sqrt{ }$ & $\sqrt{ }$ & $\sqrt{ }$ \\
PHBS & $\sqrt{ }$ & $\sqrt{ }$ & & \\
\hline
\end{tabular}

\section{Data Analysis}

Participant characteristics. Data for drop-out participants was included in the descriptive analysis to provide information on participant retention and characteristics.

Feasibility outcomes. Reported as total number of participants and enhanced by qualitative analysis of feedback questionnaires, examined using content analysis

247 (Vaismoradi, Turunen \& Bondas, 2013). Content analysis assessed numbers of similar answers from different respondents, and provided an overview of opinions and experiences of group members regarding the intervention.

Clinical outcomes. Outliers were checked on quantitative measures. One outlier was noted in follow-up data for intervention participants. For information, analysis was run with

252 and without the outlier. To refine likely effect sizes and inform future sample size

253 calculations for subsequent trials Cohen's D was calculated for the PPRFQ, MAAS and

254 PAAS. Baseline and follow-up means and standard deviations (SD) were used for intervention participants. The PHBS sample was too small for effect size calculations. 
257 statistical tests were performed. Means and standard deviations (SDs) for all quantitative

258 measures are reported.

259 Results

260 Participant Characteristics

261

Demographic data was collected from the 20 participants who completed at least one

262 dataset (see Table 4).

263

264

265

266

267

268

269

270

271

272

273

274

275

276

277

278

279

280 


\begin{tabular}{|c|c|c|c|c|c|}
\hline \multicolumn{2}{|c|}{ Characteristic } & \multirow{2}{*}{$\begin{array}{c}\begin{array}{c}\text { Intervention } \\
\mathrm{n}=11\end{array} \\
1\end{array}$} & \multirow{2}{*}{$\begin{array}{c}\begin{array}{c}\text { Control } \\
n=9\end{array} \\
1\end{array}$} & \multirow{2}{*}{$\begin{array}{c}\text { Total } \\
N=20\end{array}$} & \multirow{2}{*}{$\begin{array}{c}\begin{array}{c}\text { Drop-out } \\
n=6\end{array} \\
0\end{array}$} \\
\hline Age range: & Less than 29 years & & & & \\
\hline & 30-39 years & 10 & 7 & 17 & 6 \\
\hline & $40-50$ years & 0 & 1 & 1 & 0 \\
\hline \multirow[t]{2}{*}{ Sex: } & Male & 5 & 4 & 9 & 2 \\
\hline & Female & 6 & 5 & 11 & 4 \\
\hline \multirow[t]{4}{*}{ Ethnicity: } & White & 8 & 8 & 16 & 4 \\
\hline & Black/Black British & 1 & 0 & 1 & 0 \\
\hline & Mixed & 1 & 1 & 2 & 2 \\
\hline & Other & 1 & 0 & 1 & 0 \\
\hline \multirow[t]{2}{*}{ Marital Status: } & Single & 7 & 0 & 7 & 4 \\
\hline & Married & 4 & 9 & 13 & 2 \\
\hline \multirow[t]{4}{*}{ Education: } & A/AS Level & 2 & 2 & 4 & 1 \\
\hline & First degree (BSc/BA) & 3 & 3 & 6 & 2 \\
\hline & Higher degree (MA/PHD) & 5 & 4 & 9 & 3 \\
\hline & NVQ/HNC/HND & 1 & 0 & 1 & 0 \\
\hline $\begin{array}{l}\text { Mental health } \\
\text { Difficulties: }\end{array}$ & Yes & 4 & 2 & 6 & 2 \\
\hline \multirow[t]{2}{*}{ Gestation } & $2^{\text {nd }}$ Trimester & 3 & 5 & 8 & 4 \\
\hline & $3^{\text {rd }}$ Trimester & 8 & 4 & 12 & 2 \\
\hline $\begin{array}{l}\text { First } \\
\text { pregnancy: }\end{array}$ & Yes & 10 & 6 & 16 & 4 \\
\hline Pregnancy: & Single & 11 & 9 & 20 & 6 \\
\hline Other children: & Yes & 1 & 2 & 3 & 1 \\
\hline Miscarriage: & Yes & 0 & 3 & 3 & 1 \\
\hline Terminations: & Yes & 1 & 0 & 1 & 1 \\
\hline
\end{tabular}


HADS scores across conditions and time-points

\begin{tabular}{|c|c|c|c|c|c|c|}
\hline & \multicolumn{3}{|c|}{ Baseline } & \multicolumn{2}{|l|}{ Post } & \multirow{2}{*}{$\begin{array}{l}\text { Follow-up } \\
\text { Mean }(\mathrm{SD})\end{array}$} \\
\hline & $\mathrm{n}$ & $\operatorname{Mean}(\mathrm{SD})$ & $\mathrm{n}$ & $\operatorname{Mean}(\mathrm{SD})$ & $\mathrm{n}$ & \\
\hline \multicolumn{7}{|c|}{ Intervention } \\
\hline HADS-A & 11 & $5.27(4.20)$ & 10 & $5.10(3.76)$ & 6 & $3.67(4.59)$ \\
\hline HADS-D & 11 & $2.64(2.20)$ & 10 & $2.70(2.31)$ & 6 & $1.50(3.21)$ \\
\hline \multicolumn{7}{|l|}{ Control } \\
\hline HADS-A & 9 & $5.10(2.71)$ & - & - & 8 & $4.13(2.64)$ \\
\hline HADS-D & 9 & $1.44(1.94)$ & - & - & 8 & $2.00(2.07)$ \\
\hline
\end{tabular}

288

289

\section{Feasibility outcomes}

290

Uptake and retention

Research was completed between October 2017 and January 2018. Forty-six people

292 expressed interest when approached by the researcher $(n=34)$ or contacted the researcher

$293(\mathrm{n}=12)$. Thirty-three $(72 \%)$ agreed to take part, with $28(85 \%)$ consenting and being

294 randomised $(n=9 ; 27 \%$ conversion from researcher approaching, $n=11 ; 92 \%$ conversion from them contacting researcher). Fifteen (54\%) were randomised to the intervention condition and $13(46 \%)$ to the wait-list control. Eleven (73\%) intervention participants completed the

297 group, baseline and post measures, and six completed follow-up measures. Nine (69\%) wait298 list participants completed baseline data, with 8 retained at follow-up (see Figure 1).

299 (Insert fig 1)

$300 \quad$ Fig 1 Flow diagram to show participant uptake and retention 
There were no missing responses from quantitative questionnaires. One intervention

303 participant did not complete the HADS at time 2. On the qualitative feedback questionnaire,

304 missing responses to open-ended questions were low (7\%).

305

306

307

308

Closed question responses from feedback questionnaire

\begin{tabular}{llc}
\hline \multicolumn{1}{c}{ Question } & Response N=11 \\
\hline Attended with a partner & Yes & 6 \\
& No & 5 \\
Timing of group in pregnancy & Too early & 0 \\
& About right & \\
& Too late & 9 \\
Length of the group & Too long & 2 \\
& About right & \\
& Too short & 0 \\
& & 10 \\
\hline
\end{tabular}

\section{Intervention evaluation}

The fidelity checklist identified that group timings needed amending. Part 2 'social and unique baby' overran by approximately 15 minutes, meaning parts 5 and 6 were rushed. All groups overran by approximately 30 minutes and it was not possible to complete the plan of 'when/where/how' participants would complete activities, due to insufficient time

\section{Feedback Questionnaire}

See Table 6 for responses from closed questions on the feedback questionnaire.

Table 6
314 
Summary of themes from feedback questionnaire

\begin{tabular}{|c|c|c|}
\hline Theme & $\mathrm{N}$ & Illustrative quotes (participant ID) \\
\hline \multicolumn{3}{|l|}{ Positive Group Aspects } \\
\hline \multirow[t]{3}{*}{ Right timing in pregnancy } & 10 & 'Past 33 weeks (worrying stage), not too tired, have more energy'(P3) \\
\hline & & 'Found it really good to be in a group where mothers to be were at different stages in pregnancy'(P4) \\
\hline & & 'Good timing as baby is moving more and I'm beginning to wonder more about its development'(P11) \\
\hline \multirow[t]{3}{*}{ Discussions/shared experience } & 6 & 'Really good discussions and didn't feel rushed'(P4) \\
\hline & & 'Could have talked all day and discussed what's been happening during pregnancy'(P7) \\
\hline & & 'I had experienced/could relate to a lot of the things we discussed'(P9) \\
\hline \multirow[t]{4}{*}{ Helpful booklet } & 6 & 'Excellent, great tips/ideas in a very digestible format'(P3) \\
\hline & & 'Lots of info and good you can write your views'(P4) \\
\hline & & 'clear concise and not too overwhelming as you can be bombarded with information in \\
\hline & & pregnancy’(P8) \\
\hline \multirow[t]{2}{*}{ Good session length } & 3 & 'Perfect length after long day at work'(P3) \\
\hline & & 'It was right, we all had the opportunity to speak...'(P2) \\
\hline \multirow[t]{2}{*}{ Validating experience } & 3 & '...this session has helped to reinforce what I am doing so far has a purpose'(P7) \\
\hline & & '...felt nice to validate some of the things we've been doing'(P8) \\
\hline
\end{tabular}




\section{Group Improvements:}

Length/Structure

Changes to content

\section{D Scan footage}

Amazing baby

Baby interacting in womb
3 '...more time discussing life changes after birth'(P2)

'How to be more social with baby and going through the special Baby CHAT pack'(P8)

7 'Have more of them! Thought it was great!! Would love follow up group meetings with same group if possible please!!'(P4)

'Too short'(P5)

'Allocate more time for the whole thing as it seems to overrun 1 hour'(P6)

'Maybe a follow-up session (perhaps after babies are born)'(P9)

7 'It is impressive to see all the activity that is going on in there!'(P2)

'Amazing and fascinating!'(P3)

'...seeing the baby mouth a word was fascinating'(P4)

'Really brought things to life for me' (P8)

4 'Really amazing facial expressions'(P6)

'I particularly liked the facial expressions which I hadn't really thought about at all'(P8)

'Great- seeing the face move to the voices and it playing with new faces'(P11)

2 'Fascinating to think how much they're interacting and moving without realising'(P8)

'Seeing the face move to the voices and it playing with new faces'(P11) 


\section{Relating content to my}

baby:

Importance of interacting

Future activities

Becoming social

Imagining self as a parent
6 'I know baby can hear my voice and is probably responding with facial expressions. Definitely with kicks and movements'(P7)

'Yes that the baby could be influenced from outside and respond'(P10)

'Made me think about what it is doing/feeling'(P11)

6 'I will definitely think more about 'special times' and reflecting on their (baby's) mood/temperament to think about/choose ideas of what to do'(P8)

'Lots of info to use in the future'(P10)

'The activities-making time for a routine/interaction with the pregnancy'(P11)

5 'How the baby thinks when young'(P1)

'Importance of communication pre/post-birth'(P3)

'The conversation with your baby is important and worthwhile'(P10)

4 '...reflect on how I am feeling now about my baby's birth'(P3)

'After birth my baby will be more social and familiar with myself and partner's voice'(P7)

'About how to communicate with a relative new-born'(P9) 
Table 8

Means and SDs for intervention and control groups

\begin{tabular}{|c|c|c|c|c|c|c|}
\hline & $\mathrm{n}$ & $\operatorname{Mean}(\mathrm{SD})$ & $\mathrm{n}$ & $\operatorname{Mean}(\mathrm{SD})$ & $\mathrm{n}$ & $\operatorname{Mean}(\mathrm{SD})$ \\
\hline & \multicolumn{2}{|r|}{ Baseline } & \multicolumn{2}{|r|}{ Post } & \multicolumn{2}{|r|}{ Follow-up } \\
\hline \multicolumn{7}{|l|}{ Reflective Functioning } \\
\hline PPQRF (Intervention) & 11 & $69.27(10.73)$ & 11 & $70.72(11.11)$ & 6 & $69.17(15.78)$ \\
\hline Outlier removed & & & & & 5 & $75.2(10.73)$ \\
\hline PPQRF (Control) & 9 & $56.22(11.21)$ & - & - & 8 & $58.00(11.71)$ \\
\hline \multicolumn{7}{|l|}{ Bonding } \\
\hline MAAS (Intervention) & 6 & $80.50(4.18)$ & 6 & $80.43(4.83)$ & 3 & $87.67(7.02)$ \\
\hline MAAS (Control) & 5 & $77.4(5.90)$ & - & - & 4 & $79.00(7.62)$ \\
\hline PAAS (Intervention) & 5 & $66.60(3.36)$ & 5 & $68.8(4.49)$ & 3 & $71.00(9.64)$ \\
\hline PAAS (Control & 4 & $59.50(4.2)$ & - & - & 4 & $61.00(8.25)$ \\
\hline \multicolumn{7}{|l|}{ Maternal Health } \\
\hline PHBS (Intervention) & 6 & $57.00(6.20)$ & - & - & 3 & $61.00(7.00)$ \\
\hline PHBS (Control) & 5 & $62.00(2.92)$ & - & - & 4 & $62.00(3.37)$ \\
\hline
\end{tabular}

Effect sizes

To calculate within-group effect sizes, means and SDS for baseline and follow-up

330 data were used (see Table 7). This continuous data was normally distributed, so Cohen's D

331 was appropriate (Lakens, 2013). The PPRFQ showed a very small effect size $(d=0.007)$.

332 Without the outlier PPRFQ data showed a medium effect size $(d=0.68)$. MAAS/PAAS mean

333 scores $(d=0.77)$ showed a medium effect size. 
Discussion

335 This study assessed feasibility and acceptability of 'Baby CHAT', a novel intervention to

336 improve RF and bonding in expectant parents. Findings indicated participants can be

337 accessed and recruited. Eighty-five percent of potential participants consented to participate

338 in the study and were randomised. The intervention was well received by parents as indicated

339 by their positive feedback. However, there was difficulty retaining intervention participants at

340 follow-up. The efficacy of Baby CHAT needs to be assessed in an appropriately powered,

341 trial. Feasibility of research methods, acceptability of the intervention, clinical implications

342 and strengths and limitations are discussed.

$343 \quad$ Feasibility of research methods

$344 \quad$ Uptake

A high proportion of people who agreed to take part converted to participants (85\%).

346 Those who contacted the researcher were more likely to become active participants (92\%),

347 which could be because people were more motivated. More people were approached by the

348 researcher, however the conversion rate for them participating was lower (27\%).

\section{Retention}

350 Control participants were successfully retained at follow-up. However, this was more

351 difficult with intervention participants (45\% dropout). Drop out participants were more likely

352 to be women, in their second trimester. Two intervention participants who dropped out were

35333 and 36 weeks' gestation, meaning they could have given birth before completing follow-

354 up measures or that participants' motivation decreased after group attendance. Previous

355 research has also suggested practical reasons, like time constraints, could explain retention

356 difficulties (Frew et al., 2014). Future Baby CHAT research should consider how

357 intervention follow-up retention could be improved and should allow for this proportion of

358 drop-out. 


\section{Questionnaires}

Quantitative questionnaires were valid, reliable, and acceptable to participants, evidenced by few omitted responses. However, the intervention does not target health behaviours, so the PHBS may not be needed. Additionally, the post intervention data may be superfluous because measures are designed to capture feelings over the previous two-weeks. Therefore, future studies should only collect intervention data at baseline and two-week follow-up.

The PPRFQ follow-up intervention data showed one outlier, with a lower score than previous responses (baseline $=72$, post $=74$, follow-up $=39$ ). This did not match bonding scores or qualitative feedback from this participant. The lower follow-up RF score could suggest that after reflecting on the group their RF decreased.

\section{Effect size}

Varying effect sizes were calculated across measures ranging from very small to medium. This makes it difficult to provide recommendations for future trials. Due to the small sample and variation in calculations, a conservative estimate for future trials is preferable, therefore, a small to medium effect size is recommended.

\section{Intervention Acceptability}

Baby CHAT was acceptable to participants who reported valuing group content and discussions. They described being surprised at their baby's social capabilities and reported they could relate content to their baby. This suggests Baby CHAT enabled participants to think about their baby as a social being, which is important in developing RF. It could change the way they respond to their baby, for example making time for activities like singing that may enhance bonding, and enhance responsive parenting abilities (Smaling et al., 2016). The theme 'imagining self as a parent' suggests participants displayed a key element of RF, to think about themselves as a parent to their unborn baby (Slade et al., 2005). 

extend group length and for further sessions. A follow-up session may give participants the opportunity to further discuss activities, which could increase the impact of the intervention to improve RF and bonding.

\section{Clinical Implications}

Baby CHAT shows promise as a brief antenatal parenting intervention with potential to positively influence RF and bonding. Traditional antenatal interventions often focus on physical aspects of pregnancy (McMillan, Barlow, \& Redshaw, 2009) however; psychological preparation for parenthood is equally important (Winston \& Chicot, 2016).

Baby CHAT can provide an intervention to help expectant parents with psychological adjustments. Improving RF and bonding enables parents to become responsive and sensitive caregivers (Sadler et al., 2016) which promotes healthy infant development (Underdown \& Barlow, 2012). Therefore, it could protect children against mental or physical health difficulties, which could have lasting benefits into adulthood. This preventative strategy could reduce pressures on mental health services. This brief cost-effective group could be easily be incorporated into existing antenatal care. The time-limited nature of Baby CHAT is designed keeping in mind time constraints of NHS clinicians'.

\section{Strengths and limitations}

To our knowledge, this is the first intervention aiming to enhance RF and bonding in

403 both expectant parents in a single group session. Findings suggest Baby CHAT is valued by expectant parents and could be an important addition to antenatal care. However, a larger scale RCT should assess efficacy. Research involving fathers is sparse (Panter-Brick et al., 2014), however we recruited similar numbers of expectant mothers and fathers which is a

407 positive step in increasing fathers' involvement in parenting research. 
409 participants about study design. The sample included mostly well-educated, middle or upper

410 socio-economic status rather than other groups. Further Baby CHAT research should seek to

411 assess its usefulness in more diverse socio-economic populations.

\section{Conclusion}

413 The current study demonstrates feasibility and acceptability of Baby CHAT, a novel

414 psychoeducational parenting intervention for expectant couples. Baby CHAT may improve

415 RF and bonding in expectant parents, which could have positive outcomes for babies. Further

416 research should test efficacy and effectiveness, in a larger-scale study by examining the

417 impact of Baby CHAT on RF and bonding in a large diverse sample. Future research could

418 also include clinical populations for example those with mental health difficulties. This

419 feasibility study is an important first step in understanding the positive effects of Baby CHAT

420 on antenatal care and could have significant value in clinical settings for antenatal

421 populations. 


\section{References}

Bammens, A., Adkins, T., \& Badger, J. (2015). Psycho-educational intervention increases reflective functioning in foster and adoptive parents. Adoption \& Fostering, 39(1), 38 50. https://doi.org/10.1177/0308575914565069

Bateman, A., \& Fonagy, P. (2010). Mentalization based treatment for borderline personality disorder. World Psychiatry: Official Journal of the World Psychiatric Association (WPA), 9(1), 11-15. https://doi.org/10.1002/j.2051-5545.2010.tb00255.x

Belsky, J., \& de Haan, M. (2011). Annual research review: Parenting and children's brain development: The end of the beginning. Journal of Child Psychology and Psychiatry, and Allied Disciplines, 52(4), 409-428. https://doi.org/10.1111/j.14697610.2010.02281.x

Bjelland, I., Dahl, A. A., Haug, T. T., \& Neckelmann, D. (2002). The validity of the hospital anxiety and depression scale. An updated literature review. Journal of Psychosomatic Research, 52(2), 69-77. https://doi.org/10.1016/S0022-3999(01)00296-3

Breustedt, S., \& Puckering, C. (2013). A qualitative evaluation of women's experiences of the mellow bumps antenatal intervention. British Journal of Midwifery, 21(3), 187-194. https//:doi.org/10.12968/bjom.2013.21.3.187

Condon, J. T. (1993). The assessment of antenatal emotional attachment: Development of a questionnaire instrument. The British Journal of Medical Psychology, 66 ( Pt 2)(Pt 2), 167-183. https://doi.org/10.1111/j.2044-8341.1993.tb01739.x

Condon, J.T., \& Corkindale, C.J. (1998). The assessment of parent-to-infant attachment: Development of a self-report questionnaire instrument. Journal of Reproductive and Infant Psychology, 16, 57-76. https://doi.org/10.1080/02646839808404558 
Daglar, G. \& Nur, N. (2018). Level of mother-baby bonding and influencing during pregnancy and postpartum period. Psychiatria Danubina, 30(4), 433-440. https://doi.org/10.24869/psyd

Day, C., Morton, A., Ibbeson, A., Maddison, S., Pease, R., \& Smith, K. (2014). Antenatal/Postnatal promotional guide: Evidence-based intervention. Journal of Health Visiting, 2(12), 658-669. https://doi.org/10.12968/johv.2014.2.12.658

deJong-Pleij E. A. P., Ribbert, L. S. M., Pistorius, L. R., Tromp E., Mulder, E. J. H., \& Bilardo, C. M. (2013). Three-dimensional ultrasound and maternal bonding, a third trimester study and a review. Prenatal Diagnosis, 33(1), 81-88. https://doi.org/10.1002/pd.4013

DeLuca, R. S., \& Lobel, M. (1995). Conception, commitment, and health behavior practices in medically high-risk pregnant women. Women's Health (Hillsdale, N.J.), 1(3), 257271. https://doi.org/10.1624/105812407X192019

Foley, S., \& Hughes, C., (2018). Great expectations? Do mothers' and fathers' prenatal thoughts and feelings about the infant predict parent-infant interaction quality? A metaanalytic review. Developmental Review, 48, 40. https://doi.org/10.1016/j.dr.2018.03.007

Frew, P. M., Saint-Victor, D. S., Isaacs, M. B., Kim, S., Swamy, G. K., Sheffield, J. S., ... Ault, K. (2014). Recruitment and retention of pregnant women into clinical research trials: An overview of challenges, facilitators, and best practices. Clinical Infectious Diseases: An Official Publication of the Infectious Diseases Society of America, 59 Suppl 7, S400-7. https://doi.org/10.1093/cid/ciu726

Glover, V., \& Capron, L. (2017). Prenatal Parenting. Current Opinion in Psychology, 15, 6670. https://doi.org/10.1016/j.copsyc.2017.02.007

Goecke, T.W., Voigt, F., Faschingbauer. F., Spangler, G., Beckman, M.W., \& Beetz, A. (2012). The association of prenatal attachment and perinatal factors with pre- and 
postpartum depression in first-time mothers. Archives of Gynecology and Obstetrics, 286(2), 309-316. https://doi.org/10.1007/s00404-012-2286-6

Hijazi, Z. R., \& East, C. E. (2009). Factors affecting maternal perception of fetal movement. Obstetrical \& Gynecological Survey, 64(7), 489-97. https//:doi.org/10.1097/OGX.0b013e3181a8237a

Ji, E. K., Pretorius, D. H., Newton, R., Uyan, K., Hull, A. D., Hollenbach, K., \& Nelson, T.R. (2005). Effects of ultrasound on maternal-fetal bonding: A comparison of two- and three-dimensional imaging. Ultrasound in Obstetrics \& Gynecology: The Official Journal of the International Society of Ultrasound in Obstetrics and Gynecology, 25(5), 473-477. https://doi.org/10.1002/uog.1896

Lakens, D. (2013). Calculating and reporting effect sizes to facilitate cumulative science: A practical primer for t-tests and ANOVAs. Frontiers in Psychology, 4, 863. https://doi.org/ 10.3389/fpsyg.2013.00863

Lee, A. M., Lam, S. K., Sze Mun Lau, S. M., Chong, C. S., Chui, H. W., \& Fong, D. Y. (2007). Prevalence, course, and risk factors for antenatal anxiety and depression. Obstetrics and Gynecology, 110(5), 1102-1112. https://doi.org/ 10.1097/01.AOG.0000287065.59491.70

Lindgren, K. (2001). Relationships among maternal-fetal attachment, prenatal depression, and health practices in pregnancy. Research in Nursing \& Health, 24(3), 203-217. https://doi.org/10.1002/nur.1023

Lobel, M., Cannella, D. L., Graham, J. E., DeVincent, C., Schneider, J., \& Meyer, B. A. (2008). Pregnancy-specific stress, prenatal health behaviors, and birth outcomes. Health Psychology: Official Journal of the Division of Health Psychology, American Psychological Association, 27(5), 604-615. https://doi.org/ 10.1037/a0013242

Lobel, M., DeVincent, C. J., Kaminer, A., \& Meyer, B. A. (2000). The impact of prenatal maternal stress and optimistic disposition on birth outcomes in medically high-risk 
women. Health Psychology: Official Journal of the Division of Health Psychology, American Psychological Association, 19(6), 544-553. https://doi.org/10.1037//0278-

Maggi, S., Irwin, L. J., Siddiqi, A., \& Hertzman, C. (2010). The social determinants of early child development: An overview. Journal of Paediatrics and Child Health, 46(11), 627635. https://doi.org/10.1111/j.1440-1754.2010.01817.x

Maskell-Graham, D. (2014). Peep reflective parenting programme (pilot): A therapeutic intervention beginning in late pregnancy. brief interim findings: Main messages. https://www.peeple.org.uk/sites/www.peeple.org.uk/files/Reflective\%20Parenting\%20St

McMillan, A. S., Barlow, J., \& Redshaw, M. (2009). Birth and beyond: A review of the evidence about antenatal education. Department of Health.

510 NHS Choices. (2016). Birth to 5 developmental timeline.

511 http://www.nhs.uk/Tools/Pages/birthtofive.aspx. Accessed 24 May 2018

512 NHS Choices. (2017a). Pregnancy and baby. http://www.nhs.uk/conditions/pregnancy-and-

513 baby/pages/pregnancy-weeks-4-5-6-7-8.aspx. Accessed 24 May 2018

514 NHS Choices. (2017b). You and your baby at 17-20 weeks pregnant.

515 http://www.nhs.uk/conditions/pregnancy-and-baby/pages/pregnancy-weeks-17-18-19-

$516 \quad$ 20.aspx. Accessed 24 May 2018

517 Pajulo, M., Tolvanen, M., Karlsson, L., Halme-Chowdhury, E., Ost, C., Luyten, P., ...

518 Karlsson, H. (2015). The prenatal parental reflective functioning questionnaire:

519 Exploring factor structure and construct validity of a new measure in the Finn Brain

520 Birth Cohort pilot study. Infant Mental Health Journal, 36(4), 399-414.

521 https://doi.org/10.1002/imhj.21523 
522 Panter-Brick, C., Burgess, A., Eggerman, M., McAllister, F., Pruett, K., \& Leckman, J. F. 523 (2014). Practitioner review: Engaging fathers--recommendations for a game change in 524 parenting interventions based on a systematic review of the global evidence. Journal of 525 Child Psychology and Psychiatry, and Allied Disciplines, 55(11), 1187-1212.

526 https://doi.org/ 10.1111/jcpp.12280

527 Pretorius, D. H., Gattu, S., Ji, E. K., Hollenbach, K., Newton, R., Hull, A., ...Nelson, T.R. 528 (2006). Preexamination and postexamination assessment of parental-fetal bonding in 529 patients undergoing 3-/4-dimensional obstetric ultrasonography. Journal of Ultrasound 530 in Medicine: Official Journal of the American Institute of Ultrasound in Medicine, $531 \quad$ 25(11), 1411-1421. https://doi.org/10.7863/jum.2006.25.11.1411

532 Reissland, N. (2017). Your unborn baby and you. https://www.youtube.com/playlist?list=PLVgdBqk8pbT5R924IjMwe4iSN30ELKMDx. Accessed 21 April 2018

Reissland, N., Francis, B., Buttanshaw, L., Austen, J. M., \& Reid, V. (2016). Do fetuses move their lips to the sound that they hear? An observational feasibility study on auditory stimulation in the womb. Pilot and Feasibility Studies, 2(1), 1. https://doi.org/10.1186/s40814-016-0053-3

Reissland, N. Froggatt, S., Reames, E., \& Girkin, J. (2018). Effects of maternal anxiety and 540 depression on fetal neuro-development. Journal of Affective Disorders, 241, 469-74. $541 \quad$ https://doi.org/10.1016/j.jad.2018.08.047

542 Righetti, P. L., Dell'Avanzo, M., Grigio, M., \& Nicolini, U. (2005). Maternal/paternal 543 antenatal attachment and fourth-dimensional ultrasound technique: A preliminary report. 544 British Journal of Psychology (London, England: 1953), 96(Pt 1), 129-137.

$545 \quad$ https://doi.org/10.1348/000712604X15518 
546 Roberts, J. (2012). 'Wakey wakey baby': Narrating four-dimensional (4D) bonding scans.

547 Sociology of Health \& Illness, 34(2), 299-314. https://doi.org/10.1111/j.1467-

$548 \quad 9566.2011 .01345 . x$

549 Rossen, L., Hutchinson, D., Wilson, D., Burns, L., Olsson, C., Allsop, S.,... Mattick, R.P. 550 (2016). Predictors of postnatal moth-infant bonding: the role of antenatal bonding, maternal substance use and mental health. Journal of Women's Mental Health,

552 19(4), 609-22. https://doi.org/10.1007/s00737-016-0602-z.

553

Rustico, M. A., Baietti, M. G., Coviello, D., Orlandi, E., \& Nicolini, U. (2005). Managing twins discordant for fetal anomaly. Prenatal Diagnosis, 25(9), 766-771.

555 https://doi.org/10.1002/pd.1260

556

Sadler, L.S., Slade, A., Close, N., Webb, D. L., Simpson, T., Fennie, K., \& Mayes, L. C.

557 (2013). Minding the Baby: Enhancing Reflectiveness to Improve Early Health and Relationship Outcomes in an Interdisciplinary Home-Visiting Program. Infant Mental Health Journal, 34(5): 391-405. https://doi.org/10.1002/imhj.21406

Sadler, L. S., Novick, G., \& Meadows-Oliver, M. (2016). "Having a baby changes everything" reflective functioning in pregnant adolescents. Journal of Pediatric Nursing,

562 31(3), e219-31. https://doi.org/10.1016/j.pedn.2015.11.011

563

Slade, A., Grienenberger, J., Bernbach, E., Levy, D., \& Locker, A. (2005). Maternal reflective functioning, attachment, and the transmission gap: A preliminary study. Attachment \& Human Development, 7(3), 283-298. https://doi.org/10.1080/14616730500245880

Slade, A., Grunebaum, L., Huganir, L., \& Reeves, M. (2011). The Pregnancy Interview, 568 Revised. New York: City College of New York.

569 Smaling, H. J., Huijbregts, S. C., van der Heijden, K. B., Hay, D. F., van Goozen, S. H., \& 570 Swaab, H. (2017). Prenatal reflective functioning and development of aggression in 
573 Snaith, R. P., \& Zigmond, A. S. (1994). HADS: Hospital anxiety and depression scale.

$574 \quad$ Windsor: NFER Nelson.

575 Taylor, A., Atkins, R., Kumar, R., Adams, D., \& Glover, V. (2005). A New Mother-to-Infant

576 Bonding Scale: Links with Early Maternal Mood. Archives of Women's Mental Health, $577 \quad 8,45-51$.

578 Underdown, A., \& Barlow, J. (2012). Maternal emotional wellbeing and infant development:

$579 \quad$ A good practice guide for midwives.

580 https://www.rcm.org.uk/sites/default/files/Emotional\%20Wellbeing_Guide_WEB.pdf.

$581 \quad$ Accessed 30 January 2018

582 Vaismoradi, M., Turunen, H., \& Bondas, T. (2013). Content analysis and thematic analysis:

583 Implications for conducting a qualitative descriptive study. Nursing \& Health Sciences, 584 15(3), 398-405. https://doi.org/ 10.1111/nhs.12048

585 Winston, R., \& Chicot, R. (2016). The importance of early bonding on the long-term mental 586 health and resilience of children. London Journal of Primary Care, 8(1), 12-14. $587 \quad$ https://doi.org/10.1080/17571472.2015.1133012

588 Zigmond, A. S., \& Snaith, R. P. (1983). The hospital anxiety and depression scale. Acta $589 \quad$ Psychiatrica Scandinavica, 67(6), 361-370. http://doi.org/10.1111/j.1600-

$590 \quad$ 0447.1983.tb09716.x 